\title{
Effect of Psycho-educational Intervention for Obese Women Post Bariatric Surgery on Body Image and Self-esteem.
}

\section{Asmaa Taha Altaheri ${ }^{1}$, Mervat Mostafa El Gueneidy ${ }^{2}$, Mervat Hosny Shalaby ${ }^{3}$, Nagla Fathi El- $\operatorname{Attar}^{4}$}

(1)Assistant Lecturer of Psychiatric and Mental Health Nursing, Faculty of Health Sciences/ Al Saeed University, (2)Professor of Psychiatric Nursing and Mental Health, Faculty of Nursing / Alexandria University, (3)Professor of Psychiatric Nursing and Mental Health, Faculty of Nursing / Tanta University and (4)Assistant professor of Psychiatric and Mental Health Nursing, Faculty of Nursing/ Benha University

\begin{abstract}
Background: Bariatric is a branch of medicine dealing with the causes, prevention, and treatment of obesity. It leads to massive and rapid weight loss in severely obese patients. This may result in numerous complications that affect body image satisfaction and self-esteem. Aim of the study: Was to evaluate the effect of a psycho-educational intervention for obese women after bariatric surgery on body image and self-esteem. Study design: A quasi-experimental design was followed. Study setting: This study was conducted in two settings namely the surgical department at University Hospital in Benha and the Gastroenterology ward in the Main University hospital in Alexandria. Subject: A convenient sample of 40 women who had bariatric surgery constituted the study subject. They were divided into two equal groups randomly; a study group that received the nursing psychological educational intervention and a control group that was exposed to routine care only. Tools of the study: Rosenberg Self-Esteem Scale and the Multidimensional body self-relations questionnaire appearance scale (MBSRQ-AS) and socio-demographic and clinical characteristics sheet. Results: Study group who received psychoeducational program show higher mean in self-esteem scale than the control group with Mean \pm SD (33.55 \pm 2.25 and 29.10 \pm 2.59 respectively) with highly statistical significant difference between the study and control group. Also, the Mean \pm SD of different domains of body image satisfaction in study group were higher than control group with highly statistical significant differences. Conclusion: The psychoeducational program implementation had a positive effect in self-esteem and all domains of body image satisfaction for studied subjects undergoing bariatric surgery. Recommendation: Psycho educational programs should be offered for obese women' undergoing bariatric surgery as a regular and integral component of health care.
\end{abstract}

Key words: Obesity, Bariatric surgery, Psycho educational, Self-esteem, Body image

\section{Introduction}

Obesity is now considered as a chronic disease, causing an increased likelihood of developing comorbidities, such as diabetes, hypertension, cardiovascular syndromes, respiratory abnormalities and psychiatric conditions (Kyrou et al., 2018). Data published by the World Health Organization revealed that in 2016 more than 1.9 billion adults were 
overweight. Obesity has approximately tripled since 1975 and has become a worldwide epidemic. It is recently the focus of numerous studies (WHO, 2018).

Obese person usually exposure to weight stigma that effect negatively on body image satisfaction and self-esteem level (Wu and Berry, 2018), Also the obese women exposed to discrimination and sarcasm that lead to social isolation, loneliness, poor body image satisfaction, and low self-esteem (Jung and Sikorski, 2019, Mehrdad et al., 2015, Ozcanarslan et al., 2018).

Bariatric is a branch of medicine dealing with the causes, prevention, and management of obesity (Odom, 2017). Weight loss is attained by reducing the size of the stomach through an implanted of medical device (gastric banding) or by removal of a portion of the stomach (biliopancreatic diversion with duodenal switch or sleeve gastrectomy) or through resecting and re-routing the small intestines to a small stomach pouch (gastric bypass surgery) (Rothrock, 2018). A person is considered a candidate for bariatric surgery, if Body Mass Index (BMI) is higher than $40 \mathrm{~kg} / \mathrm{m}^{2}$ or above $35 \mathrm{~kg} / \mathrm{m}^{2}$ in the presence of associated comorbidities e.g. type II diabetes, sleep apnea, arterial hypertension and others (Wolfe et al., 2016).

Bariatric surgery leads to massive and rapid weight loss in severely obese patients (Maciejewski et al., 2016). This may result in numerous complications that affect the body image satisfaction and self-esteem. Thus, the increase loose and/or sagging skin after surgery are as high as $89.2 \%$. Moreover extensive scars add to the dissatisfaction with body image (Aldaqal et al., 2013). (Tovar et al., 2014) also found that hair loss after bariatric surgery is more frequent in female patients and may lead to changes in body image and low selfesteem.

Many post bariatric surgery patients stated that they hold unrealistic expectations about the bariatric outcomes. Some may anticipate that bariatric surgery will result in a total body transformation that makes their bodies comparable to persons who never experienced excessive body weight. Others may not fully understand that bariatric surgery cause skin hanging especially in the areas of chest and abdomen, large and visible scars, skin irregularities, as well as residual deformities in body shape. In this respect, the role of psychiatry and psychiatric nursing is to manage bariatric surgery patients' and to evaluate the patients' expectations and their degree of satisfaction about the results of bariatric surgery (Gelinas et al., 2013).

Mental health nurses play a significant role in obesity psychological pre and postoperative assessment to help patients adjust to the post-operative lifestyle and subsequent emotional, behavioral, and social changes that often occur (Edwards and Wedin, 2015). Furthermore, the assessment of psychiatric status, pre and post bariatric surgery, and treatment if needed, play a crucial role in maximizing successful postoperative outcomes (Malik et al., 2014). Therefore, currently the preoperative psychosocial assessment is the standard care for patients undergoing bariatric surgery. Comprehensive assessments include the information that assist both the patient and 
the management team, anticipate and prepare patients for challenges associated with extensive behavioral and lifestyle changes that are required post bariatric surgery (Edwards and Wedin, 2015).

In addition, psycho educational intervention was found to have a positive effect on post bariatric surgery patients outcomes who attend at least four sessions of psycho education intervention were experienced greater improvements in social function and showed better in general health aspects of quality of life (Lent et al., 2019). Also , (Wild et al., 2017) found that psycho educational intervention for bariatric patients shows sustained greater effects on both depression severity scores and self-efficacy.

\section{Significance of the study:}

Egypt has high percentage of obese adults. Around nineteen million Egyptians i.e. $35 \%$ of the adult population are obese (Collaborators, 2017). Study about obesity in 24 African countries exhibited that Egypt has the highest level of overweight and obesity (Amugsi et al., 2017). The same study confirmed that the prevalence of overweight and obesity among urban women has rapidly increased in the last two and half decades.

Obesity is increasingly conceptualized and accepted as a chronic illness caused by a complex interchange of genetic, behavioral, environmental, and physiological factors (Garvey et al., 2014). Moreover results in body image dissatisfaction and low self-esteem in turn lead to harmful health behaviors such as non-adherence to diet recommendations after surgery, and the emergence of eating disorders such as anorexia, bulimia and body dysmorphia. Thus, this study sought to investigate the effect of psycho-educational intervention for obese women after bariatric surgery on body image and self-esteem.

\section{Aim of the study}

The aim of the present study was to evaluate the effect of psycho-educational intervention for obese women after bariatric surgery on body image and self-esteem

\section{Research Hypothesis:}

Obese women after bariatric surgery who attended a psycho-educational intervention will show better satisfaction with body image and higher self-esteem than those who did not.

\section{Subject and Method}

Research design: A quasi-experimental design was followed to fulfill the aim of this study.

Research Setting: This study was conducted in two settings; the general surgical ward and the outpatient clinics of University Hospital in Benha and the Gastroenterology ward and the outpatient clinic of the Main University hospital in Alexandria.

\section{Sample:}

A convenient sample of 40 women who had bariatric surgery constituted the study subject. The number of subjects with the following inclusion criteria was selected over a period 6 months.

Inclusion criteria: The patients, involved in this study were selected according to the following criteria:

- Obese Female patients admitted for bariatric surgery,

- Willing to participate in the study

- More than 18 years old,

- Free from co-morbid psychiatric disorders. 
Subjects were divided into two equal groups randomly; a study group who received the nursing psycho-educational intervention and control group who were exposed to routine care only

\section{Tools of the study:}

The study data was collected using the following tools:

\section{Socio-demographic and clinical data} structured interview this was attached to the tools of the study. It was developed by the researcher and comprised the Sociodemographic data and Clinical data related to study subjects such as, age, education, marital status, residence, occupation, role in family, presence of chronic illness, behavioral approaches for weigh management, Wight/Body Mass Index, family history of overweight, diet pattern pre and post bariatric surgery, exposure to discrimination, being ridiculed, available of psychosocial support as well as the impact of obesity on their social relationship.

\section{Tool I: Rosenberg Self-Esteem Scale (RSE):}

Rosenberg Self-Esteem Scale (RSE) was developed by (Rosenberg, 1965). It is composed of 10 items that measure overall feeling of self-worth and self- acceptance. It is used to measure global self-esteem. Arabic version of Rosenberg Self-Esteem Scale was used in Egypt and showed to be valid and reliable (Arafat et al., 2017).

\section{Scoring system of Rosenberg Self-Esteem}

Scale was as follow; $34-40$ score was considered high self-esteem, 23-33 score was considered moderate self -esteem and 22 and less score was considered low self-esteem.
Tool II: The Multidimensional body selfrelations questionnaire appearance scale (MBSRQ-AS)

It is composed of 34-items, developed by (Cash 1990) to assess body image. MBSRQ-AS proved to be valid and reliable on Egyptian population (Alkholy, 2018). (MBSRQ-AS) is well validated measure that evaluates appearance related component of body image and each (MBSRQ-AS) is the mean of its subscale score It is used to assess Appearance Evaluation (7 items), Appearance Orientation (12 items), Body Areas Satisfaction (9 items), Overweight Preoccupation (4 items), and SelfClassified Weight (2 items) (Cash, 2000).

Scoring system of (MBSRQ-AS) as followed; A 5-point Likert Scale; a low score of "1" indicates that the participant highly disagrees with a given statement, whereas a high score of 5 indicates that the participant highly agrees with it. Higher scores reflect greater satisfaction with the specific domain (MacKean et al., 2010).

\section{Validity and Reliability:}

- Tool I was translated into Arabic language and back-translated into English by (Arafat et al., 2017) tool proved to be valid and reliable on Egyptian population; Cronbach's alpha test up to 0.88

- Tool II was translated into Arabic language and retranslated into English by (Alkholy, 2018) tool proved to be valid and reliable on Egyptian population; Cronbach's alpha test $=0.76$

\section{Pilot study:}

A pilot study was carried out to test the clarity, feasibility and applicability of tools as well as to estimate the time needed for data collection. Few modifications were made on sociodemographic and clinical data sheet such as 
exposure to discrimination, and sarcasm, social relationship and availability of psychosocial support.

\section{Field work:}

Data collection was carried out over 10 months from August 2019 to May 2020. Through individual interview the Nursing Psychoeducational Interventions for obese women patients undergoing bariatric surgery was conducted throughout 4 phases:

\section{I: Assessment phase:}

During this phase, the researcher met the study subjects individually for the initial assessment. A consent was obtained from each patient after the explanation the purpose of the study. Baseline data for both groups such as age, education, marital status, residence, occupation, past history, treatment, Wight/Body Mass Index, family history of overweight, diet pattern was collected. Additionally, Body image and self-esteem were assessed for both groups (before psychoeducational program) each interviewed last about 30 minutes.

\section{II: Planning and development phase:}

During this phase the researcher developed the psychoeducational intervention according to pretest assessment by using tools I and II and review of related literature.

\section{III: Implementation phase:}

This phase began by data collection then implementation of a psycho-educational intervention for patients who met previously mentioned inclusion criteria in nine sessions. Each session was continued for approximately 60 minutes.

\section{Sessions (I): Introductory session: (Theoretical)}

Time required: 60 minutes

Setting: The Gastroenterology Ward.

\section{Aims of the first session :}

- Emphasize rapport between patients and researcher

- Identify the purpose of the program.

- Orient patients about the program and its expected outcomes.

- Describe schedule of the program.

- Outline the content of the program .

\section{Contents :}

- Introduction

- Expected outcomes

- Aim of the program

- Schedule of the program.

- Content of the program

\section{Method of teaching:}

- Discussion

- Face to face interview

\section{Media used:}

- Booklet

\section{Evaluation method:}

- Feedback through oral question/ pretest questionnaire

\section{Sessions (2 and 3): Theoretical part:} Time required: 60 minutes

Setting: The Gastroenterology Ward and out patients clinic.

\section{Aim of the theoretical sessions:}

At the end of the above sessions, the patients will be able to:

- Define the obesity and Body Mass Index

- Recognize the physical and psychological causes of obesity.

- Enumerate the complication of obesity

- Discuss the different methods of treatment of obesity

- Identify the bariatric surgery 
- Count the reasons for bariatric surgery and it is complications.

- Discuss the importance of healthy food

- Explain the importance of adherence to dietitian advice.

- Show off the importance of the activity for physical and mental health status postbariatric surgery

- Demonstrate the past experiences of activity and exercise and how to take up new interests and activities

\section{Content:}

Definition of the obesity, classifications of the obesity, causes of obesity, consequences of obesity, psychological consequences of obesity, psychosocial concern related to obesity, methods of obesity treatment, bariatric surgery, types of bariatric surgery, complications of bariatric surgery, how to cope with complication of bariatric surgery, healthy food behaviors, the importance of adherence to dietitian advice, as well as allowed and unallowed food after bariatric surgery.

\section{Method of teaching:}

- One to one instruction

- Group Discussion

- Brainstorming

\section{Media used:}

- Booklet

- Colored Pictures

\section{Evaluation method:}

- Feedback through oral question

\section{Sessions (4, 5, 6, 7 and 8): Practical part}

Time required: 60 minutes

Setting: Out patients clinic.

Aim of the practical sessions:

- Explore the psychosocial influences (trigger for eating)

- Identify the unhealthy behavior, pattern, beliefs, and attitudes about eating

- Discuss the stimulus control techniques and coping strategies to deal with unhealthy eating behavior.

- Understand the meaning of body image

- Recognize the reasons for negative body image

- Know different methods to improve body image satisfaction

- Explore the different aspect of caring for their body

- Practice the assertiveness techniques against negative comments

- Encourage patient to express their feeling about their body

- Apply the different methods of coping with low self-esteem

- Learn the approaches that can be used to alleviate anxiety

- Apply deep breathing exercise to decrease stress

- Use muscle relaxation and other techniques e.g. Yoga, Meditation

- Illustrate the importance of body exercises and a healthy lifestyle 
- Modify their lifestyle in order to improve body image satisfaction and improve selfesteem

- $\quad$ List the exercises that used to improve their body appearance

- Show of the different approaches to relieve the depression

- Illustrate the importance of friendships and social support to decrease loneliness and social isolation.

\section{Contents:}

The reason of unhealthy eating and its psychological management, exercise how to overcome on psychosocial influences for unhealthy eating behaviors, skills to improve body image satisfaction, practices that affect negatively on body image satisfaction, how to care for their body, relaxation techniques, physical exercises, different methods to improve self-esteem, modify the lifestyle, different strategies to reduce stress, and importance of social support.

\section{Method of teaching:}

- Discussion, Role play, Demonstration and re demonstrations

\section{Media used:}

- Booklet , Pictures , Audiovisual , Color pens and cards, Paper and pen

\section{Evaluation method:}

- Feedback through oral question, re demonstration and positive participation.

\section{Session (9): Ending of the psychoeducational program (last session)}

Setting: out patients clinic.

Time required for session: 60 minutes

\section{Aim of this session :}

At the end of this session the patients will be able to recall the main points of the program's content.

\section{Contents:}

Revision of the program's content was done and researcher welcomed and required clarification.

\section{Methods of teaching:}

- Discussion and demonstration

\section{Media used:}

- Booklet and Flipchart.

\section{Methods of evaluation:}

- Feedback, redemonstration and positive participation

Suitable teaching aids prepared specially for the program were: booklet (handout), videos, and pictures. At the end of every session, the patient's questions were discussed to clarify any misunderstanding that happened during it.

\section{Phase IV: - Evaluation phase :}

Three months followed the implementation of psycho educational intervention, each subject in the study group and control group was interviewed to evaluate her body image and self-esteem using the tool I and II. A comparison between the study and control groups was done. 


\section{Ethical considerations:}

The ethical research consideration in this study include the following:

- No name was included in the questionnaire sheet.

- The researcher has clarified the objectives and the aims of the study to each subject included in the study assuring the anonymity and confidently of data

- Subjects were informed that they were allowed to choose to participate or refuse in the study and they have the right to withdraw at any time.

\section{Statistical design}

- The Statistical Package for Social Sciences (SPSS) program version 25.0 was utilized for data analysis.

- Frequency tables and cross-tabulations were employed to clarify the results of categorical data and tested by the Chi Square Test or Fisher's Exact Test.

- Qualitative data were described using numbers and percent, and quantitative data were described using mean and standard deviation.

- Comparison between both groups were carried out using independent $t$ test and paired $\mathrm{t}$ test for the quantitative variable while Chi-Square $\left(\chi^{2}\right)$ for qualitative variables.

- The level of significance selected for this study was $\mathrm{P}$ equal to or less than 0.05 .

\section{Limitations of the study}

- Due to the COVID-19 pandemic, the last cases were followed up at 3 months postsurgery through phone contact.

\section{Results:}

Table ( 1): revealed that $47.5 \%$ of studied subjects, age ranged between $35-<45$ years old with Mean $\pm \mathrm{SD}=37.05 \pm 8.52$ years old, $45.0 \%$ were married, $42.5 \%$ had basic education, $52.5 \%$ were not working and $77.5 \%$ were living in an urban area.

Table (2) shows that $80.0 \%$ of the studied subjects have a chronic illness. Body mass index for $55.0 \%$ was more than 45 , and most of the studied subjects have tried previous methods of weight loss as diet, exercise, diet and exercise, or use of medications

Table (3) shows that the majority of the studied subjects in both groups were exposed to sarcasm and discrimination and their social relation was affected due to the obesity as well they did not receive any psychosocial support

Table (4) shows that $70.0 \%$ and $65.0 \%$ respectively of the subjects in the study and control groups pre-implementation of psycho educational program had low self-esteem without any statistical significant difference between the two groups pre-implementation of the psycho educational program with $(\chi 2=0.114$ $\mathrm{P}=1.000$ ). After the implementation of the psycho educational program, $95.0 \%$ of the study group had moderate self-esteem as compared to $75.0 \%$ of the control group with statistically significant difference $(\chi 2=6.471$ $\mathrm{P}=0.039$ ). In the same line, the mean of the self-esteem was higher in the study group than the control group with 33.55 \pm 2.25 , and $29.10 \pm 2.59$ respectively with a statistically significant difference between the study and control group $\left(\mathbf{X}^{2}=0.189 \mathrm{P}=0.00\right)$

Table (5) shows that there were no statistically significant differences between the study and control group in all body image satisfaction domains before the implementation of the psycho educational program, while there were statistically significant differences between 
study and control groups after implementation of the psycho educational program in almost all body image satisfaction domains; appearance evaluation, appearance orientation, overweight preoccupation, body area satisfaction as well as in a total mean of body image satisfaction with $P$ value is 0.00 in all domain
(Table 6) shows that there was a statistically significant correlation between body image satisfaction and self-esteem values before and three months after the implementation of psycho educational program

Table (1): Distribution of the study and control group according to their socio-demographic characteristics

\begin{tabular}{|c|c|c|c|c|c|c|c|c|}
\hline \multirow{2}{*}{ Socio-demographic characteristics } & \multicolumn{2}{|c|}{$\begin{array}{l}\text { Study Group } \\
\quad(\mathbf{n}=\mathbf{2 0})\end{array}$} & \multicolumn{2}{|c|}{$\begin{array}{c}\text { Control Group } \\
(\mathbf{n}=\mathbf{2 0})\end{array}$} & \multicolumn{2}{|c|}{$\begin{array}{c}\text { Total } \\
(n=40)\end{array}$} & \multirow[t]{2}{*}{$\mathbf{X}^{2}$} & \multirow[t]{2}{*}{$\mathbf{P}$} \\
\hline & No. & $\%$ & No. & $\%$ & No. & $\%$ & & \\
\hline \multicolumn{9}{|l|}{ Age } \\
\hline $19-<25$ & 2 & 10.0 & 3 & 15.0 & 5 & 12.5 & \multirow{4}{*}{0.544} & \multirow{4}{*}{0.909} \\
\hline $25-<35$ & 6 & 30.0 & 5 & 25.0 & 11 & 27.5 & & \\
\hline $35-<45$ & 9 & 45.0 & 10 & 50.0 & 19 & 47.5 & & \\
\hline $45-<55$ & 3 & 15.0 & 2 & 10.0 & 5 & 12.5 & & \\
\hline $\begin{array}{l}\text { Min }- \text { Max } \\
\text { Mean } \pm \text { SD }\end{array}$ & \multicolumn{2}{|c|}{$\begin{array}{c}19-50 \\
37.2 \pm 8.62\end{array}$} & \multicolumn{2}{|c|}{$\begin{array}{c}20-52 \\
36.9 \pm 8.99\end{array}$} & \multicolumn{2}{|c|}{$\begin{array}{c}19-52 \\
37.05 \pm 8.52\end{array}$} & $\begin{array}{c}\mathrm{t}=0.11 \\
0\end{array}$ & 0.913 \\
\hline \multicolumn{9}{|l|}{ Marital status } \\
\hline Single & 5 & 25.0 & 6 & 30.0 & 11 & 27.5 & \multirow{4}{*}{0.513} & \multirow{4}{*}{0.916} \\
\hline Married & 10 & 50.0 & 8 & 40.0 & 18 & 45.0 & & \\
\hline Widowed & 3 & 15.0 & 3 & 15.0 & 6 & 15.0 & & \\
\hline Separated/Divorced & 2 & 10.0 & 3 & 15.0 & 5 & 12.5 & & \\
\hline \multicolumn{9}{|l|}{ Educational level } \\
\hline Illiterate & 2 & 10.0 & 2 & 10.0 & 4 & 10.0 & \multirow{4}{*}{0.545} & \multirow{4}{*}{0.909} \\
\hline Basic Education & 8 & 40.0 & 9 & 45.0 & 17 & 42.5 & & \\
\hline Secondary school & 2 & 10.0 & 3 & 10.0 & 5 & 12.5 & & \\
\hline Diploma/Bachelor & 8 & 40.0 & 6 & 30.0 & 14 & 35.0 & & \\
\hline \multicolumn{9}{|l|}{ Occupation } \\
\hline Working & 10 & 50.0 & 9 & 45.0 & 19 & 47.5 & \multirow{2}{*}{0.100} & $\mathrm{FET}=$ \\
\hline Not working & 10 & 50.0 & 11 & 55.0 & 21 & 52.5 & & 1.000 \\
\hline \multicolumn{9}{|l|}{ Residence } \\
\hline Rural & 3 & 15.0 & 6 & 30.0 & 9 & 22.5 & \multirow{2}{*}{1.290} & $\mathrm{FET}=$ \\
\hline Urban & 17 & 85.0 & 14 & 70.0 & 31 & 77.5 & & 0.225 \\
\hline
\end{tabular}


Table (2): Distribution of the study and control group according to their clinical characteristics

\begin{tabular}{|c|c|c|c|c|c|c|c|c|}
\hline \multirow[t]{2}{*}{ Clinical characteristics } & \multicolumn{2}{|c|}{$\begin{array}{l}\text { Study Group } \\
\quad(\mathrm{n}=\mathbf{2 0})\end{array}$} & \multicolumn{2}{|c|}{$\begin{array}{l}\text { Control Group } \\
(\mathbf{n}=20)\end{array}$} & \multicolumn{2}{|c|}{$\begin{array}{c}\text { Total } \\
(n=40)\end{array}$} & \multirow[t]{2}{*}{$\mathbf{X} 2$} & \multirow[t]{2}{*}{$\mathbf{P}$} \\
\hline & No. & $\%$ & No. & $\%$ & No. & $\%$ & & \\
\hline \multicolumn{9}{|l|}{ Presence of chronic illness } \\
\hline Yes & 15 & 75.0 & 17 & 85.0 & 32 & 80.0 & \multirow{2}{*}{0.625} & \multirow{2}{*}{$\mathrm{FET}=0.347$} \\
\hline No & 5 & 25.0 & 3 & 15.0 & 8 & 20.0 & & \\
\hline Type of chronic illness\# & \multicolumn{2}{|c|}{$\mathrm{n}=15$} & \multicolumn{2}{|c|}{$\mathrm{n}=17$} & \multicolumn{2}{|c|}{$n=32$} & \multirow[b]{2}{*}{0.173} & \multirow[b]{2}{*}{$\mathrm{FET}=0.500$} \\
\hline Hypertension & 4 & 26.7 & 3 & 17.6 & 7 & 21.9 & & \\
\hline Diabetes Mellitus & 4 & 26.7 & 6 & 35.3 & 10 & 31.3 & 0.533 & $\mathrm{FET}=0.358$ \\
\hline Arthritis & 9 & 60.0 & 7 & 41.2 & 16 & 50.0 & 0.417 & $\mathrm{FET}=0.374$ \\
\hline Others* & 4 & 26.7 & 5 & 29.4 & 9 & 28.1 & 0.143 & $\mathrm{FET}=1.000$ \\
\hline \multicolumn{9}{|l|}{ Family history of obesity } \\
\hline Yes & 9 & 45.0 & 6 & 30.0 & 15 & 37.5 & \multirow{2}{*}{0.960} & \multirow{2}{*}{$\mathrm{FET}=0.514$} \\
\hline No & 11 & 55.0 & 14 & 70.0 & 25 & 62.5 & & \\
\hline \multicolumn{9}{|l|}{ Body Mass Index } \\
\hline $30-<40$ & 5 & 25.0 & 4 & 20.0 & 9 & 22.5 & \multirow{4}{*}{2.444} & \multirow{4}{*}{0.485} \\
\hline $40-<45$ & 6 & 30.0 & 3 & 15.0 & 9 & 22.5 & & \\
\hline $45-<50$ & 4 & 20.0 & 8 & 40.0 & 12 & 30.0 & & \\
\hline$\geq 50$ & 5 & 25.0 & 5 & 25.0 & 10 & 25.0 & & \\
\hline Min - Max & \multirow{2}{*}{\multicolumn{2}{|c|}{$\begin{array}{c}33.6-55 \\
44.83 \pm 6.18\end{array}$}} & \multirow{2}{*}{\multicolumn{2}{|c|}{$\begin{array}{c}34.1-55 \\
46.53 \pm 5.97\end{array}$}} & \multirow{2}{*}{\multicolumn{2}{|c|}{$\begin{array}{c}33.6-55 \\
45.68 \pm 6.06\end{array}$}} & $\mathrm{t}=$ & \multirow{2}{*}{0.382} \\
\hline Mean \pm SD & & & & & & & -0.884 & \\
\hline \multicolumn{9}{|l|}{$\begin{array}{l}\text { Previous methods of } \\
\text { weight loss }\end{array}$} \\
\hline No & 6 & 30.0 & 5 & 25.0 & 11 & 27.5 & \multirow{5}{*}{1.324} & \multirow{5}{*}{$=0.857$} \\
\hline Diet & 4 & 20.0 & 6 & 30.0 & 10 & 25.0 & & \\
\hline Exercise & 4 & 20.0 & 4 & 20.0 & 8 & 20.0 & & \\
\hline Diet and exercise & 5 & 25.0 & 3 & 15.0 & 8 & 20.0 & & \\
\hline Medications & 1 & 5.0 & 2 & 10.0 & 3 & 7.5 & & \\
\hline
\end{tabular}

$\chi^{2}$ : Chi square test $\quad \mathrm{FE}_{\mathrm{p}} \mathrm{p}$ value for Fisher Exact

$\mathrm{P}, \mathrm{t}$ : Student $\mathrm{t}$ test

$\mathrm{p}$ : $\mathrm{p}$ value for comparing between the studied groups $\quad *$ : Statistically significant at $\mathrm{p} \leq 0.05$

\# More than one disease at one time Others* : Liver diseases, Cholelithiasis, Cardiac diseases and

GIT disorders 
Table (3): Psychosocial factors affecting the study and control group.

\begin{tabular}{|c|c|c|c|c|c|}
\hline \multirow[t]{2}{*}{ Subjects' state of Self-esteem } & \multicolumn{2}{|c|}{$\begin{array}{c}\text { Study Group } \\
(\mathrm{n}=\mathbf{2 0})\end{array}$} & \multicolumn{2}{|c|}{$\begin{array}{c}\text { Control Group } \\
(n=20)\end{array}$} & \multirow[t]{2}{*}{$\begin{array}{c}\text { Test of } \\
\text { significance }\end{array}$} \\
\hline & No. & $\%$ & No. & $\%$ & \\
\hline \multirow{4}{*}{$\begin{array}{l}\text { Before Psychoeducational intervention } \\
\leq 22 \text { (low self-esteem) } \\
22-33 \text { (Moderate Self-esteem) } \\
\geq 34 \text { (high self-esteem) }\end{array}$} & & & & & \multirow{4}{*}{$\begin{array}{c}\mathbf{X}^{2}=0.114 \\
\mathrm{FET}=1.000\end{array}$} \\
\hline & 14 & 70.0 & 13 & 65.0 & \\
\hline & 6 & 30.0 & 7 & 35.0 & \\
\hline & 0 & 0.0 & 0 & 0.0 & \\
\hline Min. - Max. & \multirow{2}{*}{\multicolumn{2}{|c|}{$\begin{array}{c}16-26 \\
21.30 \pm 2.67\end{array}$}} & \multirow{2}{*}{\multicolumn{2}{|c|}{$\begin{array}{c}16-26 \\
20.7 \pm 2.73\end{array}$}} & $\mathrm{t}=0.701$ \\
\hline Mean \pm SD. & & & & & ${ }^{\mathrm{t}} \mathrm{P}=0.488$ \\
\hline \multirow{5}{*}{$\begin{array}{l}3 \text { months after Psychoeducational } \\
\text { intervention } \\
\quad \leq 22 \text { (low self-esteem) } \\
22-33 \text { (Moderate Self-esteem) } \\
\geq 34 \text { (high self-esteem) }\end{array}$} & & & & & \multirow{5}{*}{$\begin{array}{l}\mathbf{X}^{2}=6.471 \\
* \mathrm{P}=0.039\end{array}$} \\
\hline & & & & & \\
\hline & 0 & 0.0 & 5 & 25.0 & \\
\hline & 19 & 95.0 & 15 & 75.0 & \\
\hline & 1 & 5.0 & 0 & 0.0 & \\
\hline Min. - Max. & \multicolumn{2}{|c|}{$\begin{array}{c}30-39 \\
33.55 \pm 2.25\end{array}$} & \multicolumn{2}{|c|}{$\begin{array}{c}22-33 \\
29.10 \pm 2.59\end{array}$} & $\begin{array}{l}\mathrm{t}=0.786 \\
* * *^{\mathrm{t}} \mathrm{P}=000\end{array}$ \\
\hline
\end{tabular}

$\mathbf{X}^{2:}$ for Chi square test $\mathrm{P}$, t: for Student $\mathbf{t}$ test $\quad \mathrm{FET}=$ Fisher exact test

*Significant difference at $\mathrm{P}$ level $\leq 0.05 . \quad * *$ Highly Significant difference at $\mathrm{P}$ level $\leq 0.01$

Table (4): Comparison between the studied subjects in both groups regarding level of self-esteem before and 3 months after implementation of the psycho educational program.

\begin{tabular}{|c|c|c|c|c|c|c|}
\hline \multirow[t]{2}{*}{ Psychosocial relationship } & \multicolumn{2}{|c|}{$\begin{array}{c}\text { Study Group } \\
(\mathbf{n}=\mathbf{2 0})\end{array}$} & \multicolumn{2}{|c|}{$\begin{array}{c}\text { Control Group } \\
(\mathbf{n}=\mathbf{2 0})\end{array}$} & \multirow[t]{2}{*}{$\mathbf{X}^{2}$} & \multirow[t]{2}{*}{ FET } \\
\hline & No. & $\%$ & No. & $\%$ & & \\
\hline $\begin{array}{l}\text { Exposure to sarcasm } \\
\text { Yes } \\
\text { No }\end{array}$ & $\begin{array}{c}13 \\
7\end{array}$ & $\begin{array}{l}65.0 \\
35.0\end{array}$ & $\begin{array}{c}14 \\
6\end{array}$ & $\begin{array}{l}70.0 \\
30.0\end{array}$ & 0.114 & 0.500 \\
\hline $\begin{array}{l}\text { Exposure to discrimination } \\
\text { Yes } \\
\text { No }\end{array}$ & $\begin{array}{c}13 \\
7\end{array}$ & $\begin{array}{l}65.0 \\
35.0\end{array}$ & $\begin{array}{c}15 \\
5\end{array}$ & $\begin{array}{l}75.0 \\
25.0\end{array}$ & 0.476 & 0.366 \\
\hline $\begin{array}{l}\text { Effect of obesity on social relationship } \\
\text { Yes } \\
\text { No }\end{array}$ & $\begin{array}{c}11 \\
9\end{array}$ & $\begin{array}{l}55.0 \\
45.0\end{array}$ & $\begin{array}{l}10 \\
10\end{array}$ & $\begin{array}{l}50.0 \\
50.0\end{array}$ & 0.100 & 0.500 \\
\hline $\begin{array}{l}\text { Receive psychological or social support } \\
\text { Yes } \\
\text { No }\end{array}$ & $\begin{array}{c}5 \\
15\end{array}$ & $\begin{array}{l}45.0 \\
75.0\end{array}$ & $\begin{array}{c}9 \\
11\end{array}$ & $\begin{array}{l}45.0 \\
55.0\end{array}$ & 1.758 & 0.320 \\
\hline $\begin{array}{l}\text { Source of psychosocial support } \\
\text { Family } \\
\text { Friends } \\
\text { Other patients }\end{array}$ & $\begin{array}{c}\mathrm{n}=5 \\
2 \\
2 \\
1\end{array}$ & $\begin{array}{c}\% \\
40.0 \\
40.0 \\
20.0\end{array}$ & $\begin{array}{c}\mathrm{n}=9 \\
5 \\
2 \\
2\end{array}$ & $\begin{array}{c}\% \\
55.6 \\
22.2 \\
22.2\end{array}$ & $\cdot .519$ & 0.790 \\
\hline
\end{tabular}

$\chi^{2}$ : Chi square test ${ }^{\mathrm{FE}} \mathrm{p}: \mathrm{p}$ value for Fisher Exact

$\mathrm{p}$ : $\mathrm{p}$ value for comparing between the studied groups $\quad *$ : Statistically significant at $\mathrm{p} \leq 0.05$ 
Table (5): Comparison between means of body image satisfaction and their related domain of studied subjects in both groups before and after implementation of psychoeducational program

\begin{tabular}{|c|c|c|c|c|c|c|}
\hline Q & $\begin{array}{c}\text { Body image } \\
\text { satisfaction domain }\end{array}$ & $\begin{array}{l}\text { Subjects } \\
\mathrm{N}=20\end{array}$ & $\begin{array}{c}\text { Pre } \\
\text { Mean } \pm \text { SD }\end{array}$ & $\begin{array}{l}\text { After } 3 \text { months } \\
\text { Mean } \pm \text { SD }\end{array}$ & $\mathrm{P} 1$ & $\mathrm{P} 2$ \\
\hline \multirow{2}{*}{1.} & \multirow{2}{*}{$\begin{array}{l}\text { Appearance } \\
\text { evaluation }\end{array}$} & Study & $14.25 \pm 3.52$ & $24.50 \pm 2.30$ & \multirow{2}{*}{0.531} & \multirow{2}{*}{$* * 0.00$} \\
\hline & & Control & $13.65 \pm 2.36$ & $20.80 \pm 1.98$ & & \\
\hline \multirow{2}{*}{2.} & \multirow{2}{*}{$\begin{array}{l}\text { Appearance } \\
\text { orientation }\end{array}$} & Study & $31.35 \pm 4.41$ & $45.05 \pm 2.83$ & \multirow{2}{*}{0.59} & \multirow{2}{*}{$* * 0.00$} \\
\hline & & Control & $32.05 \pm 3.81$ & $41.65 \pm 2.05$ & & \\
\hline \multirow{2}{*}{3.} & \multirow{2}{*}{$\begin{array}{l}\text { Body area } \\
\text { satisfactions }\end{array}$} & Study & $17.90 \pm 1.77$ & $23.10 \pm 1.61$ & \multirow{2}{*}{0.49} & \multirow{2}{*}{$\begin{array}{c}* * 0.00 \\
0\end{array}$} \\
\hline & & Control & $18.35 \pm 2.32$ & $20.30 \pm 2.22$ & & \\
\hline \multirow{2}{*}{4.} & \multirow{2}{*}{$\begin{array}{l}\text { Overweight } \\
\text { preoccupation }\end{array}$} & Study & $12.95 \pm 1.53$ & $10.40 \pm 2.16$ & \multirow{2}{*}{0.62} & \multirow{2}{*}{$* * 0.00$} \\
\hline & & Control & $13.15 \pm 0.98$ & $13.10 \pm 1.99$ & & \\
\hline \multirow{2}{*}{5.} & \multirow{2}{*}{ Self-classified weight } & Study & $9.6 \pm 0.75$ & $8.7 \pm 0.86$ & \multirow{2}{*}{0.30} & \multirow{2}{*}{0.525} \\
\hline & & Control & $9.8 \pm 0.41$ & $8.85 \pm 0.58$ & & \\
\hline
\end{tabular}

$\mathrm{P}=$ Student $\mathbf{t}$ test. $\quad$ *Significant difference at $\mathrm{P}$ level $\leq 0.05$.

**Highly Significant difference at $\mathrm{P}$ level $\leq 0.01$

$\mathrm{P} 1=\mathrm{p}$ value comparing between both groups pre surgery.

$\mathrm{P} 2=\mathrm{p}$ value comparing between both groups after psychoeducational intervention.

Table (6): Correlation between self-esteem and body image before and after three months of implementation of psychoeducational program in both groups.

\begin{tabular}{|c|c|c|c|c|}
\hline \multirow{2}{*}{ Correlations } & \multicolumn{4}{|c|}{ Body Image Satisfaction } \\
\cline { 2 - 5 } & \multicolumn{3}{|c|}{ Before } & \multicolumn{2}{c|}{ After 3 Months } \\
\cline { 2 - 5 } & $\mathrm{r} 1$ & $\mathrm{p} 1$ & $\mathrm{r} 2$ & $\mathrm{p} 2$ \\
\hline Self-esteem Scale & 0.669 & $\ddots \cdots$ & $\ddots \varepsilon \wedge \wedge$ & $\ddots \cdots)$ \\
\hline
\end{tabular}

R, P: Pearson correlation test

R1, P1: correlation between body image satisfaction and self-esteem scale at pre surgery in both groups.

R2, P2: correlation between body image satisfaction and self-esteem scale at post psychoeducational intervention in both groups.

\section{Discussion}

Management of obesity is not only important for the prevention of physical diseases but also for the prevention of psychiatric and emotional problems (Unlu et al., 2019). Obesity is one of the most important determinants of self-esteem scale and body image satisfactions among women. In fact body image dissatisfaction and low 
self-esteem become silent attributes in obese people. The seriousness of this matter has led to the emergence of body image therapy as a psychological approach to alleviate psychological disturbances related to obesity. The importance of body image is not confined only to self-esteem and satisfaction it also has an impact on mental health-related issues (Hamdan et al., 2019). It has also been found that poor body image and low self-esteem are more common symptoms among people with obesity leading to psychological adverse effects (Ivezaj and Grilo, 2018).

The obesity epidemic showed accelerated growth in the number of bariatric surgeries performed worldwide including Egypt. The reported number of bariatric surgeries in Egypt is around 30,000 operations annually (Sabri, 2018). Bariatric procedures result in massive weight loss that gives rapid changes in physical appearance. This may result in altered body perception that may add to the disturbed body image and self-esteem. Consequently, the current study aimed to evaluate the effect of a psychoeducational intervention for obese women after bariatric surgery on body image and self-esteem.

At pre bariatric surgery, the present study indicates that obese women undergoing bariatric surgery have worsened body image as well as self-esteem disturbances. Many causes can be explained such as the negative representation of obese women in the media as nowadays, beauty is associated with slim being. This finding is in agreement with a number of previous studies that showed that obese women have lower self-esteem and that most obese women were dissatisfied with their body image(Mar et al., 2017, Raso et al., 2016, Pop, 2016). In the same line, (Musaiger and Al-Mannai, 2013) study conducted on female university students in Kuwait showed that the majority of obese females were dissatisfied with their current weight and figure. Obese women are usually ridiculed and discriminated. This opinion is supported by numerous studies that concluded that an obese person is usually exposed to discrimination and sarcasm that lead to social isolation, loneliness, poor body image satisfaction, and low self-esteem. (Jung and Sikorski, 2019, Mehrdad et al., 2015, Ozcanarslan et al., 2018).

The result of this study may also explain the negative impact of obesity on body image and self-esteem, it showed that most of the obese women experienced discrimination and were exposed to ridicule, Society repeatedly blames the obese person for their own ill-health because of laziness and overeating. Unfortunately, in communities that thought weight discrimination might encourage individuals with obesity to lose weight, the opposite is happening.

These findings were concurrent with (Johnson et al., 2018) that showed obese women who underwent bariatric surgery had experienced weight discrimination as well as in all of the interviews of the same study, the participants recalled situations of "fatshaming" by peers, family members, and colleagues. Also, (Jackson et al., 2015) documented harmful weight-based stereotypes describing overweight and obese individuals as lazy, weak-willed, 
unsuccessful, and unintelligent. They were also represented as lacking self-discipline, having poor willpower, and are noncompliant with weight loss treatment.

Furthermore, obese people usually perceive that obesity is life threatening as obesity is usually associated with comorbidities. In general obesity also has an effect on quality of life and acceptance of self (Okop et al., 2019). In this respect, (Peralta et al., 2016) found that overweight persons feel less athletic and agile, slow, and unfit and have overall lower self-image perception than normal-weight participants. Thus, it is expected for an obese person to lose their happiness, feel hopeless and increasing their body image dissatisfaction.

Considering the effect of obesity on the social relationship, this study exhibits negative impact of obesity on social relationship that add more to low self-esteem and altered body image. This may be due to that obesity and social withdrawal are connected with social isolation results less physical activity and unhealthy eating behavior that result in an increased body mass index and lead to more isolation. These findings are concurrent with those of (Jung and Sikorski, 2019) that showed the obesity associate with higher levels of loneliness regardless of the class of obesity. On the same line, (Varela et al., 2019) showed that overweight participants score significantly higher social withdrawal than normal weight persons. However, The finding of this study is incongruent with that of (Al-Ateeq and Al-Hargan, 2014) conducted in Saudi Arabia which showed that the majority of the obese population still engage in a social environment and social life.

Regarding lack of support for obese women either from family members or friends the result of this study showed that obese women are predispose to depression, hopelessness, helplessness as well as low self-esteem. This finding is in agreement with (Kiernan et al., 2012) that indicated lack of support among overweight and obese women was prevalent, with the most obese women reporting never or rarely receiving support from members of family and friends for their weight loss efforts. Additionally, (Martínez, 2019) showed that social support has a positive effect on weight loss in women. Also, (Kvalem et al., 2016) study showed that Post-bariatric patients who live with discouraging families report episodes of overeating post-surgery while the patients who live with a supportive family did not. Also(Voller et al., 2016) stated that social support help in long-term weight loss and suggested peer sponsorship as a unique strategy to maintain proper bariatric lifestyle practices over time.

Another cause that may affect body image satisfaction and self-esteem is clothing size. The study of (Kinley, 2010) study showed that smaller and fit sizes clothes have a positive effect on body image and selfesteem particularly for younger women. Stylists in general design clothes of smaller sizes, and if obese women can fit in a smaller size, they are more satisfied. Therefore, obese women may compare themselves with model of smaller body sizes which resulting in damaged body image and self-esteem. Furthermore, fashion and thin-ideal media 
concept were found to result in more negative effect on body satisfaction as well as selfesteem (Mask and Blanchard, 2011, Boothroyd et al., 2016).

Considering, results of the study three months after implementation of psychoeducational program, the present study shows that bariatric patients who received psychoeducational intervention exhibit better self-esteem and body image satisfaction. This finding is consistent with (Williams et al., 2018) which reported that the psychoeducation intervention for bariatric surgery has a significant role in decreasing body image dissatisfaction, feeling of fatness, and body image avoidance after one and six months of bariatric surgery. Also, the current results are in agreement with (Delparte, 2016) who stated that designed psychoeducational intervention improved post-surgical outcomes, which is in the longterm beneficial to physical health, mental health, and quality of life of bariatric patients. Besides, reductions in rates of morbid obesity in the long-term may reduce the costs and resources required to treat this population, which is beneficial to society over time (Blüher, 2019).

Likewise, (Güven and Akyolcu, 2019) study showed that the patients receiving health education and follow-ups experienced improvements in physical functioning and role performance, physiological and mental health, social functioning, and vitality. In this respect, (Brown et al., 2016) found that pre-hospital assessment and education program including psychoeducation about how stress affects eating, psychological triggers of eating, negative thought as well as motivation were found to improve both compliance and weight loss outcomes following bariatric surgery. These results are inconsistent with the study of (Cassin et al., 2013) that showed six sessions for patients with bariatric or undergoing bariatric surgery had no effect on their psychosocial concerns.

Talking about self-weight classified, this study unsurprisingly showed that the patients in both groups did not show improvement in self weight classified at the post psychoeducational intervention. This finding, it could be due to that the follow up of patients in this study was within six months after bariatric surgery which is short period for patients with high body mass index to reach the healthy body weight so they were still classified as obese. This result concord with (de Zwaan et al., 2014) who reported that after bariatric surgery, appearance evaluation, and body area satisfaction improved, but the self-weight classified still did not improve. Moreover, (Rudolph and Hilbert, 2020, Song et al., 2016) showed that after bariatric surgery patients did not reach the ideal body weight after six months. Also, (Raaijmakers et al., 2017) suggested that the weight loss after bariatric surgery will stabilize as long as after one or two years. In the same line, (Campbell et al., 2018) followed up the bariatric surgery patients at three months after surgery and found that almost all patients three months of bariatric still their body mass index obese.

\section{Conclusion}

The psycho educational intervention session played an important role on 
psychological problems (Body image dissatisfaction and low self-esteem) in obese women undergoing bariatric surgery. The psychoeducational program implementation had a positive effect in self-esteem scale and all domains of body image satisfaction (appearance evaluation, appearance orientation, overweight preoccupation, body area satisfaction and self-classified weight) for studied subjects undergoing bariatric surgery.

\section{Recommendations}

Offer psycho educational programs for obese women' who undergoing bariatric surgery as a regular and integral component of health care.

\section{References}

Al-Ateeq, M., \& Al-Hargan, M. (2014). Relationships between overweight an d obesity with preferred mode of transportation and use of neighborhood facilitie s in riyadh, Saudi Arabia. Obesity and Weight Loss Theraby, 4(240), 2.

Aldaqal, S., Makhdoum, A., Turki, A., Awan, B., Samargandi, O., \& Jamjom, H. (2013). Post-bariatric surgery satisfaction and bodycontouring consideration after massive weight loss. North American journal of medical sciences, 5(4), 301.

Alkholy, A. (2018). Coping and avoidance strategies as predictors of appearance and body image in A sample of university students. Faculty of Education - Assiut University, 34(12), 58.

Amugsi, A., Dimbuene, Z., Mberu, B., Muthuri, S., \& Ezeh, A. (2017). Prevalence and time trends in overweight and obesity among urban women: an analysis of demographic and health surveys data from 24 African countries, 1991-2014. BMJ open, 7(10), e017344.

Arafat, E., Abdel-Mageed, S., \& Ramadan, F. (2017). Internalized Stigma Of Psychiatric Illness Among Patients With Schizophrenia: Its Nature And Relationship With Self Esteem Hope And Social Support. (Master), Alexandria University,

Blüher, M. (2019). Obesity: global epidemiology and pathogenesis. Nature Reviews Endocrinology, 15(5), 288-298.

Boothroyd, L., Jucker, J., Thornborrow, T., Jamieson, M., Burt, M., Barton, R., . . . Tovee, M. (2016). Television exposure predicts body size ideals in rural Nicaragua. British Journal of Psychology, 107(4), 752-767.

Brown, W., Burton, P., Shaw, K., Smith, B., Maffescioni, S., Comitti, B., . . . Nottle, P. (2016). A pre-hospital patient education program improves outcomes of bariatric surgery. Obesity surgery, 26(9), 2074-2081.

Campbell, J., Hensher, M., Neil, A., Venn, A., Otahal, P., Wilkinson, S., \& Palmer, A. (2018). An Exploratory Study: A Head-to-Head Comparison of the EQ-5D-5L and AQoL-8D for Long-Term Publicly Waitlisted Bariatric Surgery Patients Before and 3 Months After Bariatric Surgery. PharmacoEconomics-open, 2(4), 443-458.

Cash, T. (2000). The multidimensional bodyself relations questionnaire users' manual. Available from the author at www. bodyimages. com.

Cassin, S., Sockalingam, S., Wnuk, S., Strimas, R., Royal, S., Hawa, R., \& Parikh, 
S. (2013). Cognitive behavioral therapy for bariatric surgery patients: preliminary evidence for feasibility, acceptability, and effectiveness. Cognitive Behavioral Practice, 20(4), 529-543.

Collaborators, G. O. (2017). Health effects of overweight and obesity in 195 countries over 25 years. New England Journal of Medicine, 377(1), 13-27.

de Zwaan, M., Georgiadou, E., Stroh, C., Teufel, M., Köhler, H., Tengler, M., \& Müller, A. (2014). Body image and quality of life in patients with and without body contouring surgery following bariatric surgery: a comparison of pre-and post-surgery groups. Frontiers in psychology, 5, 1310.

Delparte, C. (2016). Development and Effectiveness of a Brief Dialectical Behaviour Therapy Skills Training Group for Bariatric Patients. Faculty of Graduate Studies and Research, University of Regina,

Edwards, S., \& Wedin, S. (2015). Preoperative psychological assessment of patients seeking weight-loss surgery: identifying challenges and solutions. Psychology research behavior management, 8, 263.

Garvey, W., Garber, A., Mechanick, J., Bray, G., Dagogo, S., Einhorn, D., Hurley, D. (2014). American Association of Clinical Endocrinologists and American College of Endocrinology position statement on the 2014 advanced framework for a new diagnosis of obesity as a chronic disease. Endocrine Practice.

Gelinas, B., Delparte, C., Hart, R., \& Wright, K. (2013). Unrealistic weight loss goals and expectations among bariatric surgery candidates: the impact on pre-and postsurgical weight outcomes. Bariatric Surgical Patient Care, 8(1), 12-17.

Güven, B., \& Akyolcu, N. (2019). Effects of Nurse-Led Education on Quality of Life and Weight Loss in Patients Undergoing Bariatric Surgery. Bariatric Surgical Practice and Patient Care, 15(2), 81-87.

Hamdan, A.-L., Sataloff, R., \& Hawkshaw, M. (2019). Obesity and Voice: Plural Publishing.

Ivezaj, V., \& Grilo, C. (2018). The complexity of body image following bariatric surgery: a systematic review of the literature. Obesity reviews, 19(8), 1116-1140.

Jackson, S., Beeken, R., \& Wardle, J. (2015). Obesity, perceived weight discrimination, and psychological well-being in older adults in $\mathrm{E}$ ngland. Obesity, 23(5), 1105-1111.

Johnson, L., Asigbee, F., Crowell, R., \& Negrini, A. (2018). Pre-surgical, surgical and post-surgical experiences of weight loss surgery patients: a closer look at social determinants of health. Clinical obesity, 8(4), 265-274.

Jung, F., \& Sikorski, C. (2019). Overweight and Lonely? A representative study on loneliness in obese people and its determinants. Obesity Facts, 12(4), 440-447.

Kiernan, M., Moore, S., Schoffman, D., Lee, K., King, A., Taylor, B., . . . Perri, M. (2012). Social support for healthy behaviors: scale psychometrics and prediction of weight loss among women in a behavioral program. Obesity, 20(4), 756-764.

Kinley, T. (2010). The effect of clothing size on self-esteem and body image. Family and 
Consumer Sciences Research Journal, 38(3), $317-332$.

Kvalem, I., Bergh, I., \& Mala, T. (2016). Family support for changing eating habits three years after bariatric surgery. Surgery for Obesity Related Diseases, 12(7), S50-S51.

Kyrou, I., Randeva, H., Tsigos, C., Kaltsas, G., \& Weickert, M. (2018). Clinical problems caused by obesity. In Endotext [Internet]: MDText. com, Inc.

Lent, M., Campbell, L., Kelly, M., Lawson, J., Murakami, J., Gorrell, S., . . . Petrick, A. (2019). The feasibility of a behavioral group intervention after weight-loss surgery: A randomized pilot trial. PloS one, 14(10).

Maciejewski, M., Arterburn, D., Scoyoc, L., Smith, V., Yancy, W., Weidenbacher, H., . . . Olsen, M. (2016). Bariatric surgery and longterm durability of weight loss. JAMA surgery, 151(11), 1046-1055.

Malik, S., Mitchell, J., Engel, S., Crosby, R., \& Wonderlich, S. (2014). Psychopathology in bariatric surgery candidates: a review of studies using structured diagnostic interviews. Comprehensive psychiatry, 55(2), 248-259.

Mar, M., Coll, J., Pich, J., Pons, A., \& Tur, J. (2017). Body image satisfaction and weight concerns among a Mediterranean adult population. BMC public health, 17(1), 39.

Martínez, T. (2019). The role of social support in adult women's weight loss: a literature review. Revista Salud Pública y Nutrición, 18(3), 38-44.

Mask, L., \& Blanchard, C. (2011). The effects of "thin ideal" media on women's body image concerns and eating-related intentions: The beneficial role of an autonomous regulation of eating behaviors. Body Image, 8(4), 357-365.

Mehrdad, N., Abbasi, N., \& Nasrabadi, A. (2015). The Hurt of Judgment in Excessive Weight Women: A Hermeneutic Study. Global journal of health science, 7(6), 263.

Musaiger, A., \& Al-Mannai, M. (2013). Role of obesity and media in body weight concern among female university students in Kuwait. Eating behaviors, 14(2), 229-232.

Odom, J. (2017). Drain's PeriAnesthesia Nursing-E-Book: A Critical Care Approach: Elsevier Health Sciences.

Okop, K., Levitt, N., \& Puoane, T. (2019). Weight underestimation and body size dissatisfaction among black African adults with obesity: Implications for health promotion. African journal of primary health care \& family medicine, 11(1), 1-8.

Ozcanarslan, F., Shapekova, N., \& Sancar, B. (2018). Recent Developments in Nursing and Midwifery: Cambridge Scholars Publishing.

Peralta, M., Marques, A., Martins, J., Sarmento, H., \& Costa, F. (2016). Effects of obesity on perception of ability and perception of body image in Portuguese children and adolescents. JOURNAL OF HUMAN SPORT \& EXERCISE.

Pop, C. (2016). Self-Esteem and Body Image Perception in a Sample of University Students. Eurasian Journal of Educational Research, 16(64).

Raaijmakers, L., Pouwels, S., Thomassen, S., \& Nienhuijs, S. (2017). Quality of life and bariatric surgery: a systematic review of shortand long-term results and comparison with 
community norms. European journal of clinical nutrition, 71(4), 441-449.

Raso, V., Garber, C., Mancini, R., \& Matsudo, S. (2016). Body image in a representative sample of overweight, obese and normal weight active older women living in the community: associations with body composition, physical fitness and function. MedicalExpress, 3(4).

Rosenberg, M. (1965). Rosenberg self-esteem scale (RSE). Acceptance and commitment therapy. Measures package, 61(52).

Rothrock, J. (2018). Alexander's Care of the Patient in Surgery-E-Book: Elsevier Health Sciences.

Rudolph, A., \& Hilbert, A. (2020). CognitiveBehavioral Therapy for Postbariatric Surgery Patients With Mental Disorders: A Pilot Study. Frontiers in Psychiatry, 11, 14.

Sabri, C. (2018) جرات السمنة في مصر أهم انواعها و تكلفتها.

Song, P., Patel, N., Gunther, S., Li, C.-S., Liu, Y., Lee, C., . . . Wong, M. (2016). Body image and quality of life: changes with gastric bypass and body contouring. Annals of plastic surgery, 76(Suppl 3), S216.

Tovar, J., Oller, I., Llavero, C., Zubiaga, L., Diez, M., Arroyo, A., .. . Calpena, R. (2014). Hair loss in females after sleeve gastrectomy: predictive value of serum zinc and iron levels. The American Surgeon, 80(5), 466-471.

Unlu, S., Aykut, M., Borlu, A., \& Kaner, G. (2019). Are low self-esteem and body image dissatisfaction related with body mass index? Progress in Nutrition, 21(1-S), 94-103.

Varela, C., Andrés, A., \& Saldaña, C. (2019). The behavioral pathway model to overweight and obesity: coping strategies, eating behaviors and body mass index. Eating Weight Disorders - Studies on Anorexia, Bulimia Obesity. doi:10.1007/s40519-019-00760-2

Voller, L., Dudley, K., Dwinal, R., Turner, W., Schroeder, D., \& Morton, J. (2016). Efficacy of a Peer Coaching Model in Improving Bariatric Surgery Outcomes. Surgery for Obesity Related Diseases, 12(7), S50.

WHO. (2018). Obesity and overweight Fact sheet.

Wild, B., Hünnemeyer, K., Sauer, H., Schellberg, D., Müller, B., Königsrainer, A., . . . Teufel, M. (2017). Sustained effects of a psychoeducational group intervention following bariatric surgery: follow-up of the randomized controlled BaSE study. Surgery for Obesity Related Diseases, 13(9), 1612-1618.

Williams, G., Hudson, D., Whisenhunt, B., Stone, M., Heinberg, L., \& Crowther, J. (2018). Short-term changes in affective, behavioral, and cognitive components of body image after bariatric surgery. Surgery for Obesity and Related Diseases, 14(4), 521-526.

Wolfe, B., Kvach, E., \& Eckel, R. (2016). Treatment of obesity: weight loss and bariatric surgery. Circulation research, 118(11), 18441855. 
تأثير التذخل النفسي التعليمي على صورة الجسم وتقدير الذات لاى السيدات البدينات بعد جراحة علاج السمنة أسماء طه على الطاهري - ميرفت مصطفى الجنيدي - ميرفت حسني شلبي ـ نجلاء فتحي العطار

جر احة السمنة هو فرع من فروع الطب الذي يتعامل مع أسباب السمنة وكيفية الوقاية منها و ايضا علاجها، وهى إهى

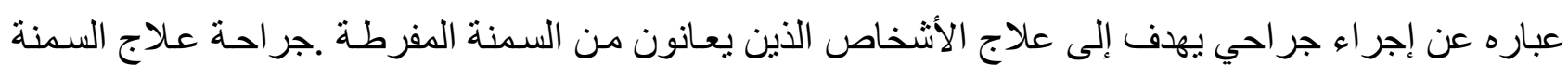

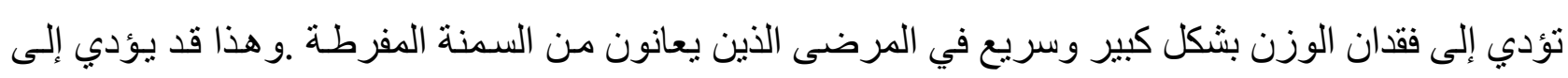

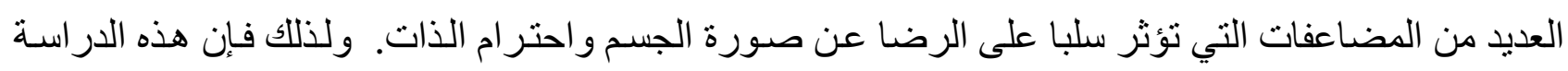

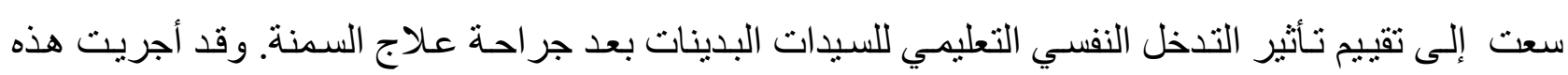

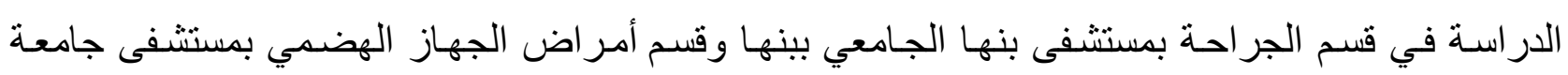

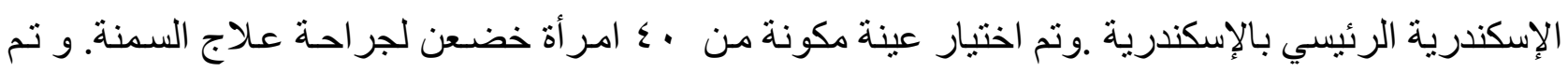

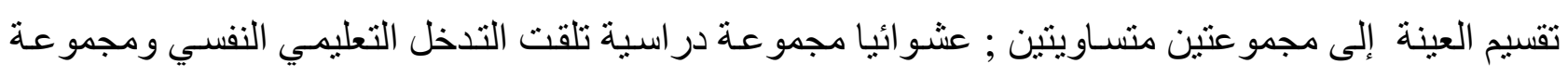

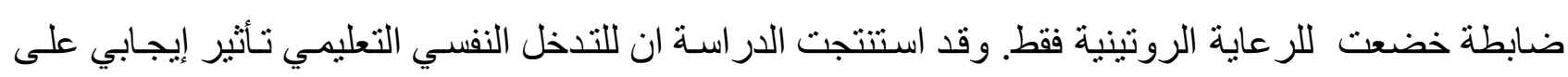

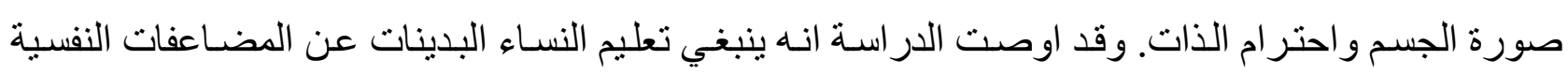

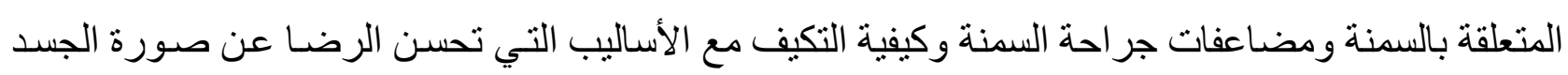
وتعزيز احترام الذات و التي سترفع من جودة الحياة بشكل عام. 